\title{
Down-Regulation of Hydrogen Sulfide Biosynthesis Accompanies Murine Interstitial Cells of Cajal Dysfunction in Partial lleal Obstruction
}

\author{
Xin Guo ${ }^{1,2}$, Xu Huang ${ }^{1}$, Yi-song Wu ${ }^{1}$, Dong-hai Liu ${ }^{1}$, Hong-li Lu ${ }^{1}$, Yong-chul Kim ${ }^{3}$, Wen-xie $\mathrm{Xu}^{1}{ }^{*}$ \\ 1 Department of Physiology, Shanghai Jiaotong University School of Medicine, Shanghai, China, 2 Department of Urology, Affiliated Hospital of Nantong University, \\ Nantong, China, 3 Department of Physiology, Chungbuk National University College of Medicine, Cheongju, Republic of Korea
}

\begin{abstract}
Purpose: To investigate the role of endogenous hydrogen sulfide $\left(\mathrm{H}_{2} \mathrm{~S}\right)$ in partial obstruction-induced dysfunction of the interstitial cells of Cajal (ICC) in mice ileum.

Materials and Methods: Partial intestinal obstruction was induced surgically in male imprinting control region (ICR) mice. ICC networks were studied by Immunohistochemistry. Electrical activity was recorded by intracellular recording techniques. The expression of ICC phenotype marker c-kit receptor tyrosine kinase (c-kit), membrane binding stem cell factor (mSCF), the endogenous $\mathrm{H}_{2} \mathrm{~S}$ biosynthesis enzymes cystathionine- $\beta$-synthase (CBS) and cystathionine- $\gamma$-lyase (CSE) was studied by Western blotting. The expression of tumor necrosis factor- $\alpha$ (TNF- $\alpha$ ) mRNA was observed by using real-time polymerase chain reaction.

Results: Partial intestinal obstruction resulted in ICC networks were disrupted above obstruction 14 days after the operation. The slow waves of intestinal smooth muscles in the dilated region were significantly suppressed and their amplitude and frequency were reduced, whilst the resting membrane potentials were depolarized. The expression of c-kit and mSCF was significantly decreased, also suggesting the disruption of the ICC network. The expression of TNF- $\alpha$ was significantly increased in the tunica muscularis of the obstructed intestine. Treatment of cultured intestinal smooth muscle cells with TNF- $\alpha$ caused dramatic down regulation of mSCF. The expression of CBS and CSE was significantly decreased in the tunica muscularis of the obstructed intestine. Intraperitoneal injection (i.p) of DL-propargylglycine, an irreversible inhibitor of CSE, and aminooxyacetic acid, an inhibitor of CBS, elevated the expression of TNF- $\alpha$ mRNA in the tunica muscularis of the ileum. Obstruction-induced over expression of TNF- $\alpha$ was significantly improved by supplementation of NaHS, but not the expressions of mSCF and c-kit.
\end{abstract}

Conclusions: The down regulation of endogenous $\mathrm{H}_{2} \mathrm{~S}$ biosynthesis is related to over expression of TNF- $\alpha$ in obstructed small intestine. TNF- $\alpha$-mediated mSCF down-regulation is not the only reason of partial intestinal obstruction-induced loss of ICC.

Citation: Guo X, Huang X, Wu Y-s, Liu D-h, Lu H-I, et al. (2012) Down-Regulation of Hydrogen Sulfide Biosynthesis Accompanies Murine Interstitial Cells of Cajal Dysfunction in Partial Ileal Obstruction. PLoS ONE 7(11): e48249. doi:10.1371/journal.pone.0048249

Editor: Hiroyasu Nakano, Juntendo University School of Medicine, Japan

Received June 27, 2012; Accepted September 21, 2012; Published November 1, 2012

Copyright: ( 2012 Guo et al. This is an open-access article distributed under the terms of the Creative Commons Attribution License, which permits unrestricted use, distribution, and reproduction in any medium, provided the original author and source are credited.

Funding: This work was supported by the National Natural Science Foundation of China (no. 31171107; 10672103; 31071011). The funders had no role in study design, data collection and analysis, decision to publish, or preparation of the manuscript.

Competing Interests: The authors have declared that no competing interests exist.

*E-mail: wenxiexu@sjtu.edu.cn

\section{Introduction}

Several congenital or acquired digestive tract motility disorders are associated with localized intestinal obstruction. Partial obstruction of the intestine has been shown to induce distention and hypertrophy of the gastrointestinal (GI) smooth muscles above the site of occlusion in both clinical situations and animal models $[1,2]$. Partial obstruction causes dramatic changes in intestinal gross morphology, interstitial cells of Cajal (ICG), and the networks and ultrastructure of smooth muscle cells [3-5]. However, little is known about the molecular changes that occur in intestinal smooth muscles in response to mechanical obstruction $[6,7]$.
In the gastrointestinal tract, the distribution of ICGs throughout the musculature is associated with nerve structures. ICCs generate a periodic depolarization at a characteristic frequency that is called the slow wave or pacemaker activity. This involves rhythmic oscillations of intracellular calcium and activation of membrane ion channels [7-9]. Importantly, ICGs express c-kit receptor tyrosine kinase. In the GI tract, development and maintenance of the ICC phenotype have been linked to intracellular signaling via c-kit [9-11]. Previous studies have indicated that ICCs are lost in partial mechanical obstruction of the GI tract, and the severest damage to the ICG network is found in the region immediately above the obstructed site [5,8]. Maintenance of the ICG network requires membrane-bound stem cell factor (mSCF) produced locally by the intestinal smooth muscles [12-15]. Previous studies 
have shown that the distended region of the intestine demonstrates inflammatory reactions, which could cause the disruption of the ICG network $[8,16,17]$. The proinflammatory cytokine tumor necrosis factor- $\alpha$ (TNF- $\alpha$ ) has been shown to be a central mediator of inflammation in the obstructed ileum. TNF- $\alpha$ has led to increased inflammatory reactions that result in the development of comprehensive muscularis inflammation in the dilated region of the intestine in obstructed mice [8]. However, it is not clear how TNF- $\alpha$ causes the disruption of the ICG network.

Hydrogen sulfide $\left(\mathrm{H}_{2} \mathrm{~S}\right)$ is a pungent gas that is formed endogenously in mammalian tissues by the $\mathrm{H}_{2} \mathrm{~S}$ biosynthesis enzymes cystathionine- $\beta$-synthase (CBS) and cystathionine- $\gamma$-lyase (CSE) $[18,19] . \mathrm{H}_{2} \mathrm{~S}$ biosynthesis has been found in the gastrointestinal tract $[20,21]$. A number of putative physiological and pathophysiological roles for this gas have been put forward, and a range of potential therapeutic uses of this gas have been proposed $[22,23]$. It is recognized that $\mathrm{H}_{2} \mathrm{~S}$ exerts complex effects on inflammation. Administration of sodium hydrosulfide (NaHS), a "fast releasing" $\mathrm{H}_{2} \mathrm{~S}$ donor, provoked an inflammatory reaction in mice [24]. However, NaHS has been reported to inhibit leukocyte adhesion to gastric mucosal blood vessels, which suggests an anti-inflammatory effect [25]. Morpholin-4-ium 4 methoxyphenyl (morpholino) phosphinodithioate (GYY4137) has been reported to slowly release $\mathrm{H}_{2} \mathrm{~S}$ over a period of hours both in vitro and in vivo. GYY4137 exhibits anti-inflammatory activity as evidenced by a reduction in the lipopolysaccharide (LPS)-induced increase in plasma proinflammatory cytokines (TNF- $\alpha$, IL-1b, IL6), nitrite/nitrate, C-reactive protein, and L-selectin in conscious rats [24]. Therefore, $\mathrm{H}_{2} \mathrm{~S}$ exerts complex and at times opposing effects on inflammation in whole animals [24,25]. These observations led us to investigate the role of endogenous $\mathrm{H}_{2} \mathrm{~S}$ in the inflammatory cytokine TNF- $\alpha$ expression in the obstructed intestine.

\section{Materials and Methods}

\section{Experimental Model}

Male imprinting control region (ICR) mice (5-weeks-old, $30 \pm$ $2 \mathrm{~g}$ ) were obtained from the Experimental Animal Center of Shanghai Jiaotong University School of Medicine. This study was carried out in strict accordance with the recommendations in the Guide for the Care and Use of Laboratory Animals of the Science and Technology Commission of P.R.C. (STCG Publication No. 2, revised 1988). The protocol was approved by the Committee on the Ethics of Animal Experiments of Shanghai Jiaotong University School of Medicine (Permit Number: Hu 686-2009). All surgery was performed under ether, and all efforts were made to minimize suffering. A total of 57 mice were used in our study. Sixteen mice were used in the obstructed model research and were divided into control group and obstructed group. 16 mice were used to study the role of endogenous $\mathrm{H}_{2} \mathrm{~S}$ in obstruction-induced intestinal inflammation and were divided into control group and treatment group. 24 mice were used to study the effect of supplementation of $\mathrm{H}_{2} \mathrm{~S}$ on expressions of TNF- $\alpha \mathrm{mRNA}, \mathrm{mSCF}$ and c-kit proteins in obstructed intestinal smooth muscle tissues. One mouse was used for intestinal smooth muscle cell culture.

Partial intestinal obstruction was induced by surgically placing a ring of silicon tube around the ileum $30-50 \mathrm{~mm}$ oral to the ileocecal sphincter to cause distension of the intestine above the site of obstruction according to the methods described by Chang et al [5] and Won et al [8]. Experiments were performed with distended segments of ileum 14 days after surgery. Control and obstruction mice were anaesthetized with ether and euthanized by cervical dislocation. A 50-mm segment of small intestine oral to the obstruction was removed and pinned out in the base of a Sylgard silicone elastomer dish containing Krebs of the following composition (mM): NaCl 118.5; KCl 4.5; $\mathrm{MgCl}_{2} 1.2 ; \mathrm{NaHCO}_{3}$ 23.8; $\mathrm{KH}_{2} \mathrm{PO}_{4}$ 1.2; glucose $11.0 ; \mathrm{CaCl}_{2}$ 2.4. The segment was opened by cutting lengthwise, washed with Krebs, and the mucosa and submucosa removed by sharp dissection [5,26]. The remaining tunica muscularis was used for electrophysiological recordings. Some of the tissues were quickly frozen in liquid nitrogen and stored at $-80^{\circ} \mathrm{C}$ for later use.

To investigate the role of endogenous $\mathrm{H}_{2} \mathrm{~S}$ in obstructioninduced intestinal inflammation, we used DL-propargylglycine (PAG, $50 \mathrm{mg} / \mathrm{kg}$ ), an irreversible inhibitor of CSE, and aminooxyacetic acid (AOA, $17 \mathrm{mg} / \mathrm{kg}$ ), an inhibitor of $\mathrm{CBS}$, to inhibit $\mathrm{H}_{2} \mathrm{~S}$ biosynthesis. The mixture solution of PAG and AOA was administered via intraperitoneal injection (i.p) twice a day for four days. The control mice were injected with same volume of phosphate-buffered saline (PBS).

To observe the effect of supplementation of $\mathrm{H}_{2} \mathrm{~S}$ on expressions of TNF- $\alpha$ mRNA, mSCF and c-kit proteins in obstructed intestinal smooth muscle tissues, obstructed mice model was established. The solution of NaHS $(10 \mathrm{umol} / \mathrm{kg})$ [27] was administered via i.p once a day for nine days from the fifth day of obstruction. The control mice were injected with same volume of PBS.

\section{Fluorescent Immunohistochemistry}

Smooth muscle strips were stretched to $110 \%$ of their resting length, fixed with ice-cold acetone $\left(4^{\circ} \mathrm{C} ; 10 \mathrm{~min}\right)$, and processed as whole mounts. Following fixation, preparations were washed for $60 \mathrm{~min}$ in phosphate-buffered saline (PBS; 0.01 M, pH 7.4). Tissues were then incubated in $10 \%$ goat serum containing $0.3 \%$ Triton $\mathrm{X}-100$ for 1 hour at room temperature to reduce nonspecific antibody binding [5,8]. For examination of ICGs, tissues were incubated overnight at $4^{\circ} \mathrm{C}$ with polyclonal (rabbit) c-Kit antibodies (sc-5535; Santa Cruz Biotechnology, Santa Cruz, CA, USA; 1:200 dilution). Immunoreactivity was detected using fluorescent isothiocyanate (FITC-488)-conjugated secondary antibody (FITC-anti-rabbit lgG; Santa Cruz Biotechnology, Santa Cruz, CA, USA; 1:400 dilution in PBS, $1 \mathrm{~h}$, room temperature).

\section{Electrophysiological Experiments}

Strips of smooth muscle $(8 \mathrm{~mm} \times 4 \mathrm{~mm})$ were cut parallel to the longitudinal axis of the intestine, oral to the site of occlusion. The smooth muscles were placed in a recording chamber with the submucosal aspect of the muscle facing upwards at $37^{\circ} \mathrm{C}$ in an atmosphere of $95 \% \mathrm{O}_{2}$ and $5 \% \mathrm{CO}_{2}$. Cells were impaled with $\mathrm{KCl}$-filled glass microelectrodes with resistances of 50-90 M $\Omega$. Electrical responses were recorded and amplified through a high input impedance amplifier (SYS-773 Duo 773 Electrometer, WPI, USA). Experiments were performed in the presence of nifedipine ( $1 \mu \mathrm{M}$; Sigma, St Louis, MO, USA) in the perfusion solution to reduce contraction and facilitate cell impalement. Slow waves in mouse intestine have been previously shown to be unaffected by nifedipine [28].

\section{Western Blotting}

Tunica muscularis or cultured intestinal smooth muscle cells were lysed in RIPA buffer (25 mM Tris-HCl pH 7.6, $150 \mathrm{mM}$ $\mathrm{NaCl}, \quad 1 \% \quad \mathrm{NP}-40, \quad 1 \%$ sodium deoxycholate, $0.1 \%$ SDS). Protein concentration was determined using the Bradford method. The lysate $(20 \mu \mathrm{g}$ of total protein per lane) was subjected to electrophoretic separation with $10 \%$ SDS-PAGE and transferred to nitrocellulose membranes (Hybond, Amersham). The membrane was incubated with $5 \%$ milk to reduce 
nonspecific antibody binding. Western blot was performed using antibodies directed against c-Kit (1:200 dilution, rabbit polyclone, Santa Cruz Technologies), mSCF (1:200 dilution, mouse monoclone, Santa Cruz Technologies), CBS (1:200 dilution, mouse monoclone, Santa Cruz Technologies), CSE (1:200 dilution, mouse monoclone, Santa Cruz Technologies), and GAPDH (1:600 dilution, rabbit monoclone, CW Biotech Company, Beijing, P.R. China). Alkaline phosphatase (AP) conjugated secondary antibodies and BCIP/NBT alkaline phosphatase color development kit (CW Biotech Company Beijing, P.R. China) were used to detect protein bands. The images were captured by Adobe Photoshop and analyzed with Quantity One image software [29].

\section{Real-time Polymerase Chain Reaction}

The mRNA expression of TNF- $\alpha$ in intestinal smooth muscle tissue was detected by real-time polymerase chain reaction (RTPCR). Specific primers for mouse TNF- $\alpha$ were $5^{\prime}$-GACGTGGAACTGGCAGAAGAG- $\quad 3^{\prime}$ and $5^{\prime}$ TTGGTGGTTTGTGAGTGtGaG - 3', (228 bp). Amplification was performed in parallel samples using glyceraldehyde-3phosphate dehydrogenase (GAPDH, 496 bp) as a control. Briefly, total RNA was isolated from smooth muscle tissue as recommended by the manufacturer of TRIzol Reagent. RNA concentration was determined by reading absorbance at $260 / 280 \mathrm{~nm}$ and was adjusted to $0.4 \mu \mathrm{g} / \mu \mathrm{L}$. Reverse transcription was performed according to the manufacturer's instructions. cDNA samples were used for PCR using specific primers for TNF- $\alpha$. The following conditions were used for PGR amplification: $95^{\circ} \mathrm{C}$ for $4 \mathrm{~min} ; 95^{\circ} \mathrm{C}$ for $30 \mathrm{sec}$; followed by 38 cycles at $58^{\circ} \mathrm{C}$ for $1 \mathrm{~min} ; 72^{\circ} \mathrm{C}$ for $30 \mathrm{sec} ; 72^{\circ} \mathrm{C}$ for $7 \mathrm{~min}$. The PCR products were separated on a 2\% agarose gel. Possible contamination of DNA was tested by skipping the reverse transcription step prior to PCR. Detectable fluorescent bands were visualized by an ultraviolet transilluminator (Bio-Rad) and the area was measured using Quantity One image software [29].

\section{Isolation and Culture of Mouse Intestinal Smooth Muscle Cells}

Intestinal smooth muscle cell (ISMC) culture was prepared from mouse intestine using an explant technique [29]. Briefly, the smooth muscle layer of the mouse intestine was surgically isolated and minced into small pieces. The tissue suspension was plated onto $25 \mathrm{~cm}^{2}$ culture flasks for culture in DMEM containing 10\% heat-inactivated fetal bovine serum (FBS), $2 \mathrm{mmol} / \mathrm{L}$ glutamine, $100 \mathrm{mmol} / \mathrm{L}$ HEPES, $100 \mathrm{U} / \mathrm{mL}$ penicillin, $100 \mathrm{mg} / \mathrm{mL}$ streptomycin, and incubated at $37^{\circ} \mathrm{C}$ in a humidified incubator containing 5\% $\mathrm{CO}_{2}$. ISMCs between passages 5-7 were used and displayed typical spindle shape morphology and a "hill-andvalley" pattern of growth. ISMCs were characterized by immunohistochemical staining for smooth muscle-specific $\alpha$-actin (Santa Cruz Biotechnology, Santa Cruz, CA, USA). DAPI was used for nuclear staining [29].

ISMCs were seeded into 6 -well plates at a density of $1 \times 10^{6}$ cells/well and incubated in $1 \mathrm{~mL}$ of serum-supplemented DMEM (10\% FBS, $1 \%$ penicillin/streptomycin) for 48 hours. Thereafter, the cell layers were washed with PBS and incubated for 24 hours in $1 \mathrm{~mL}$ of serum-free DMEM. After 24 hours, the cells were washed with PBS and incubated for 24 hours in $1 \mathrm{~mL}$ of serumfree DMEM containing $10 \mathrm{ng} / \mathrm{mL}$ of TNF- $\alpha$ (R\&D Systems $\mathrm{GmbH}$, Wiesbaden-Nordenstadt, Germany) [30]. Cells were then harvested for Western blotting.

\section{Statistical Analysis}

Data were expressed as means $\pm \mathrm{SE}$. Student's $t$-test was used to determine statistical significance. $P<0.05$ was considered statistically significant.

\section{Results}

\section{Changes in Intestinal Morphology and Electrophysiological Activity}

Partial ileal obstruction causes intestinal distention and thickening of smooth muscle layer (Figure S1) and the disrupted of ICGs (Fig. 1B) above the site of occlusion. The changes were similar to those presented previously [5]. In the gastrointestinal tract, ICCs within the smooth muscle layer generate slow waves, which elicit and control spontaneous smooth muscle contraction. Slow waves were, therefore, recorded from circular muscle strips in control and obstructed mouse intestine (Fig. 2A, 2B). The resting membrane potential (RMP) in intestinal smooth muscle cells was $-61.4 \pm 2.1 \mathrm{mV}$ in the control group, and became depolarized to $-42.8 \pm 2.5 \mathrm{mV}(\mathrm{P}<0.05)$ in the obstructed group (Fig. 2C-1). The amplitude of slow waves varied from $19.2 \pm 1.0 \mathrm{mV}$ in controls to $4.2 \pm 1.3 \mathrm{mV}(\mathrm{P}<0.01)$ in the obstructed group (Fig. 2C-2). The frequency of slow waves was $42 \pm 1.3 \mathrm{cycles} / \mathrm{min}$ in controls and declined to $32.8 \pm 1.1$ $(\mathrm{P}<0.05)$ cycles $/ \mathrm{min}$ in the obstructed group (Fig. 2C-3). These results suggest alterations of ICC function in the obstructed ileum.

\section{Effect of Partial Obstruction on the Expression of mSCF and C-Kit}

Previous studies demonstrated that ICGs were lost from the intestinal region immediately oral to the partial mechanical obstruction [5]. However, maintenance of ICGs requires mSCF produced locally by the intestinal smooth muscles [31]. Therefore, the protein expression of $\mathrm{mSCF}$ and $\mathrm{c}$-Kit was observed in partially obstructed ileum by Western blot. Representative immunoblots for mSCF, c-Kit and GAPDH from control and obstructed groups are shown in Figure 3A. Immunoblots for $\mathrm{mSCF}$ and $\mathrm{c}-\mathrm{Kit}$ indicated the presence of $\mathrm{mSCF}$ and $\mathrm{c}-\mathrm{Kit}$ proteins in the smooth muscle tissue preparations. The amount of mSCF and c-Kit proteins was significantly decreased in the obstructed group (Fig. 3B).

\section{Effect of Partial Obstruction on the Expression of TNF- $\alpha$}

Won et al [8] found that mRNA expression of TNF- $\alpha$ was significantly increased in the obstructed intestine of the rat. To determine whether similar changes happen in obstructed mouse intestine, RT-PCR analysis on RNA extracted from intestinal smooth muscle in control and obstructed mice was performed. As shown in Figure 4A, TNF- $\alpha$ mRNA was expressed in both control and obstructed groups and the ratio of TNF- $\alpha$ mRNA expression to that of GAPDH was significantly increased in obstructed mouse intestine (Fig. 4B).

\section{Effect of TNF- $\alpha$ on mSCF Expression in Cultured ISMCs}

To determine whether partial obstruction-induced decrease in mSCF expression was mediated by up-regulation of TNF- $\alpha$, ISMCs were treated with TNF- $\alpha$. Cultured ISMCs displayed typical spindle-shaped morphology and a "hill-and-valley" pattern of growth (Figure 5A-a). ISMCs were also characterized by the expression of smooth muscle-specific $\alpha$-actin (Fig. 5A-b). Anti-SCF antibody was used to detect mSCF protein in TNF- $\alpha$ and vehicletreated ISMC preparations. Representative immunoblots for mSCF and GAPDH from TNF- $\alpha$-treated and vehicle control 

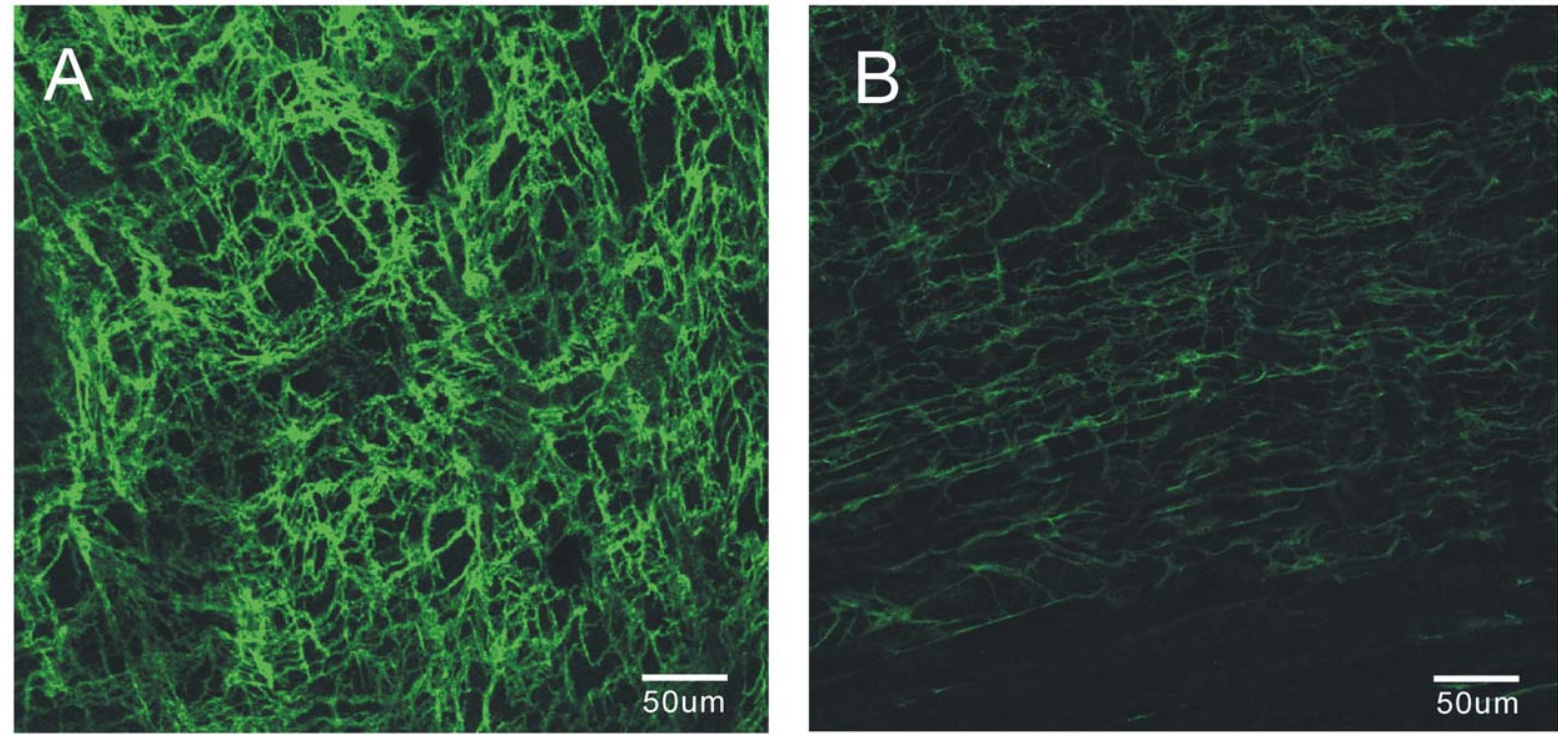

Figure 1. Fluorescent Immunohistochemistry of c-Kit in whole smooth muscle preparations. The control exhibited a dense network in the interstitial cells of Cajal (A), where this network was disrupted in the obstruction mice whole smooth muscle tissue (B). doi:10.1371/journal.pone.0048249.g001

preparations are shown in Figure 5B-a. Immunoblots for mSCF suggested that $\mathrm{mSCF}$ protein existed in the ISMCs. The ratio of corresponding mSCF/GAPDH was calculated and normalized to control. The relative expression of $\mathrm{mSCF}$ protein was significantly decreased in TNF- $\alpha$-treated ISMC preparations compared to that in vehicle control (Fig. 5B-b).
Effect of Partial Obstruction on CBS and CSE Expression

$\mathrm{H}_{2} \mathrm{~S}$ has been suggested to be proinflammatory, $\mathrm{H}_{2} \mathrm{~S}$ donating compounds have been shown to induce inflammation [24]. In addition, inhibitors of endogenous $\mathrm{H}_{2} \mathrm{~S}$ production suppress inflammation [20]. In some situations, $\mathrm{H}_{2} \mathrm{~S}$ appears to be antiinflammatory. The anti-inflammatory effect of $\mathrm{H}_{2} \mathrm{~S}$ may be

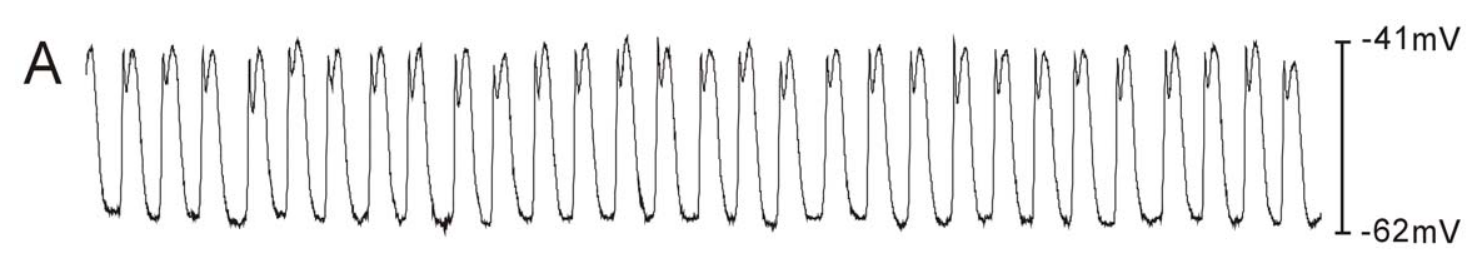

B

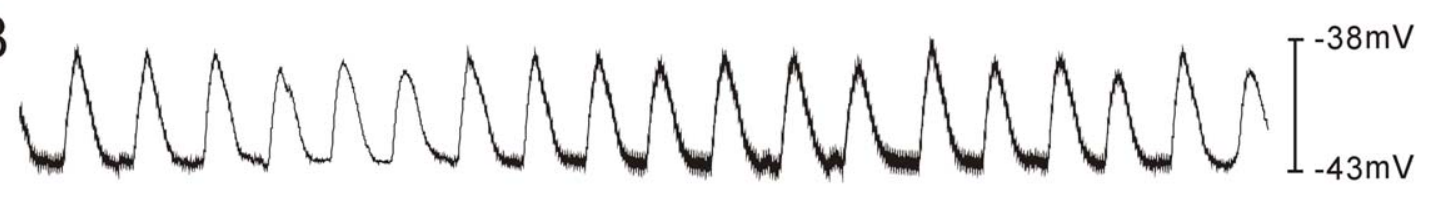

C

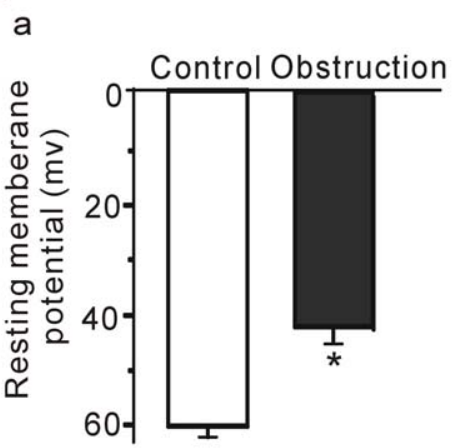

b

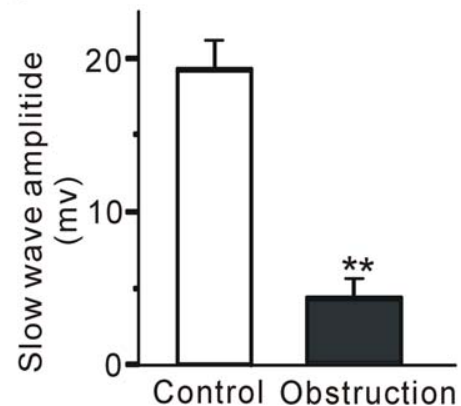

10 second

C

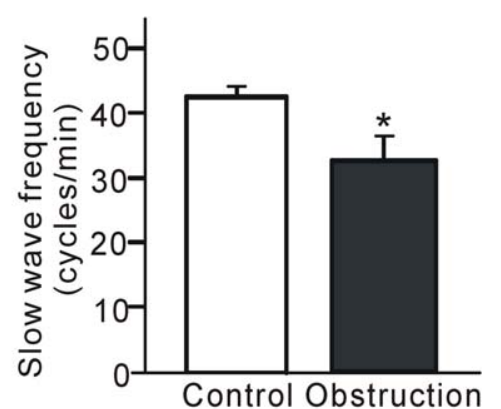

Figure 2. Electrical slow waves recorded from intestinal smooth muscle tissues. The control (A) and obstructed murine model (B). A summary of electrical parameters from control and the 14-day partial obstruction are shown in (C). C-(1), resting membrane potential (RMP); C-(2), slow wave amplitude; $\mathrm{C}-(3)$, slow wave frequency. ${ }^{*} \mathrm{P}<0.05 ;{ }^{*} \mathrm{P}<0.01 ; \mathrm{n}=8$. doi:10.1371/journal.pone.0048249.g002 
A

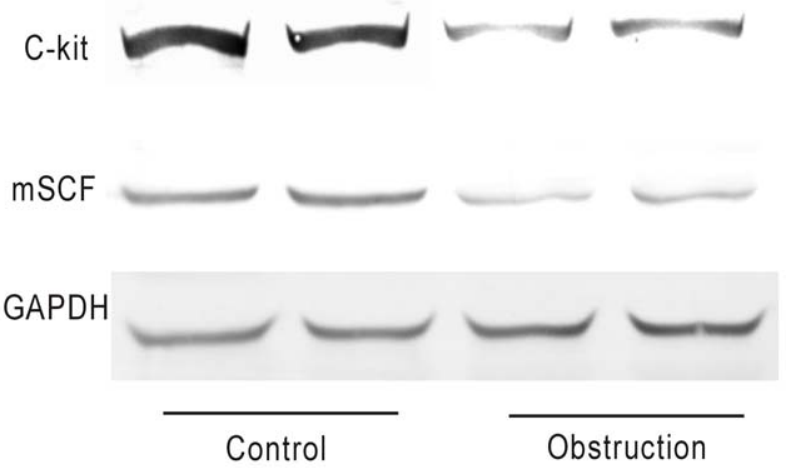

B

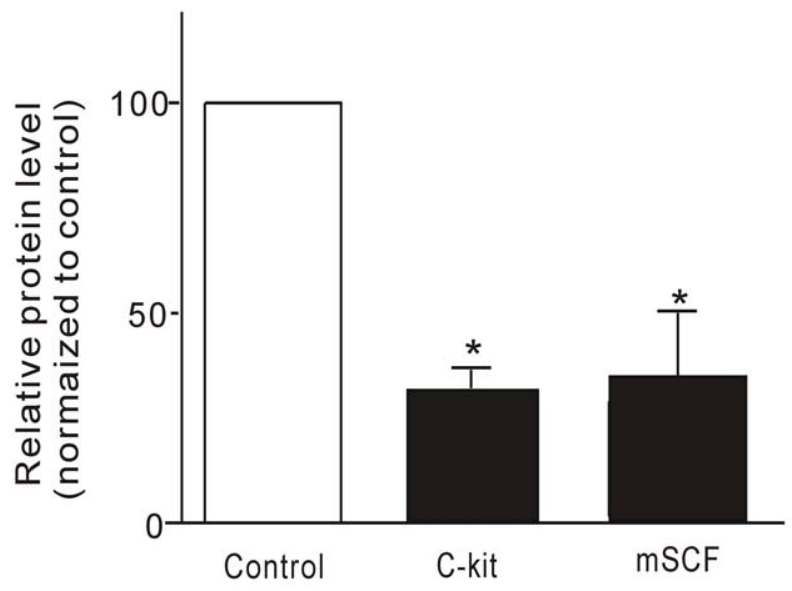

Figure 3. Western blot revealed different expression of mSCF and c-Kit between control and obstructed ileal smooth muscle tissues. A representative blot is shown in (A), whilst the densitometric quantification (\%GAPDH and normalized to control) is depicted in (B). ${ }^{*} \mathrm{P}<0.01, \mathrm{n}=8$.

doi:10.1371/journal.pone.0048249.g003

indirect, either due to its tissue-protective effect or hypothermic effect. However, $\mathrm{H}_{2} \mathrm{~S}$ may also have direct anti-infllammatory effect by acting directly on the immune system $[24,25]$. Since the inflammatory mediator TNF- $\alpha$ was increased in obstructed intestinal smooth muscle tissue, we investigated whether endogenous $\mathrm{H}_{2} \mathrm{~S}$ played a role. The expression of enzymes for $\mathrm{H}_{2} \mathrm{~S}$ biosynthesis, CSE and CBS, in the obstructed ileum was determined using Western blot. Representative immunoblots for CSE, CBS and GAPDH from control and obstructed groups are shown in Figure 6A. Relative expression of CSE and CBS proteins was significantly decreased in the obstructed group (Fig. 6B).

\section{Effects of Suppressing $\mathrm{H}_{2} \mathrm{~S}$ Biosynthesis on the Expression of TNF- $\alpha$}

To further investigate whether suppression of endogenous $\mathrm{H}_{2} \mathrm{~S}$ biosynthesis leads to the increase of TNF- $\alpha$ mRNA in obstructed intestine, the inhibitors of CSE and CBS, PAG and AOA, were administrated via intraperitoneal injection. Our results demonstrated that inhibiting $\mathrm{H}_{2} \mathrm{~S}$ biosynthesis by AOA and PAG enhanced the expression of TNF- $\alpha$ mRNA in small intestinal tissue (Fig. 7B), which suggests that endogenous $\mathrm{H}_{2} \mathrm{~S}$ may be antiinflammatory in normal gastrointestinal tract and down-regulation of $\mathrm{H}_{2} \mathrm{~S}$ biosynthesis induces increase of TNF- $\alpha$ expression in obstructed intestinal tissue.

Effect of Supplementation of $\mathrm{H}_{2} \mathrm{~S}$ on the Expressions of TNF- $\alpha$ mRNA, mSCF and c-kit Proteins in Obstructed lleal Smooth Muscle Tissues

To further investigate whether supplementation of exogenous $\mathrm{H}_{2} \mathrm{~S}$ leads to improve over expression of TNF- $\alpha$ mRNA and enhance expressions of $\mathrm{mSCF}$ and c-kit proteins in the obstructed ileal smooth muscle tissues, NaHS were administrated via i.p. The results demonstrated that supplementation of exogenous $\mathrm{H}_{2} \mathrm{~S}$ with NaHS significantly improved over expression of TNF- $\alpha$ mRNA $(\mathrm{n}=8, P<0.01$, Fig. 8A). However, the expressions of mSCF and c-kit proteins have an increasing tendency but not significantly restored $(\mathrm{n}=8, P>0.05$, Fig. $8 \mathrm{~B})$. The results suggest that endogenous $\mathrm{H}_{2} \mathrm{~S}$ may be play an anti-inflammatory effect in normal gastrointestinal tract so down-regulation of $\mathrm{H}_{2} \mathrm{~S}$ biosynthesis is related to over expression of TNF- $\alpha$ in obstructed intestinal tissue. In despite of previous study indicated that TNF$\alpha$ involved in inflammation-induced loss of ICC [8], however, over expression of TNF- $\alpha$ is not one and only reason of loss ICG in obstructed intestinal smooth muscle tissue because obstruction is a complicated pathophysiologic process.
A

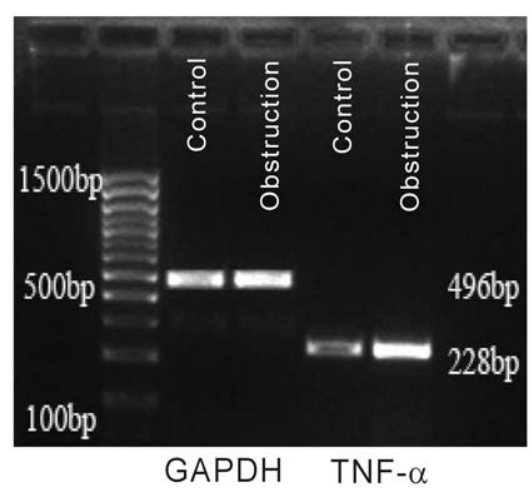

B

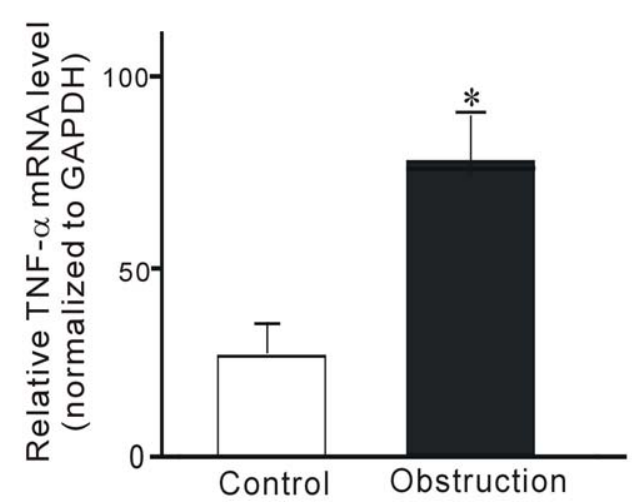

Figure 4. Expression of TNF- $\alpha$ mRNA in obstructed ileal smooth muscle tissues. (A) Expression of TNF- $\alpha$ and GAPDH mRNA. (B) Densitometric analysis of TNF- $\alpha$ and GAPDH mRNA. ${ }^{* *} \mathrm{P}<0.01, \mathrm{n}=8$.

doi:10.1371/journal.pone.0048249.g004 
A
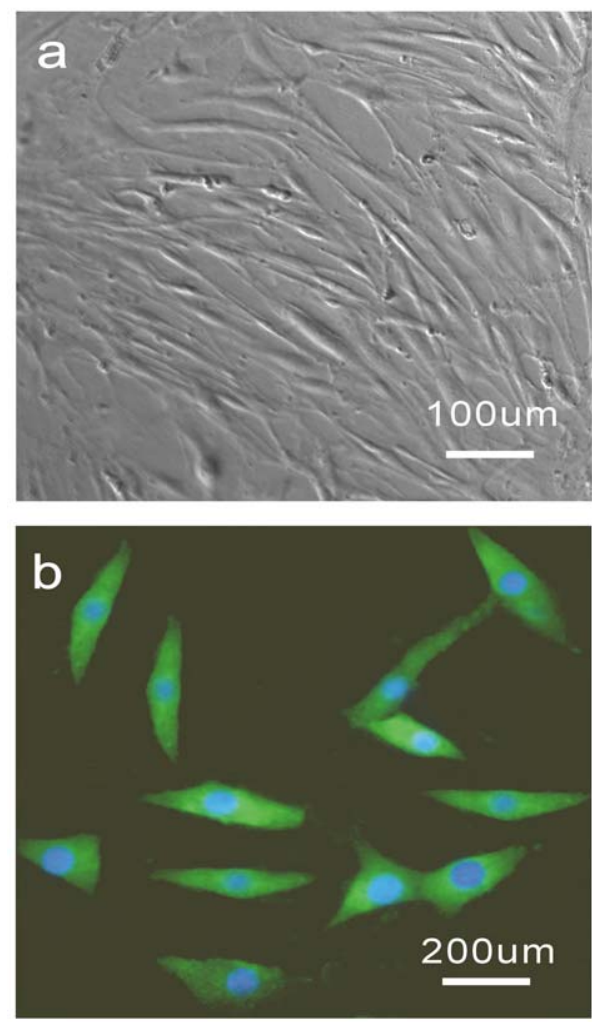

B

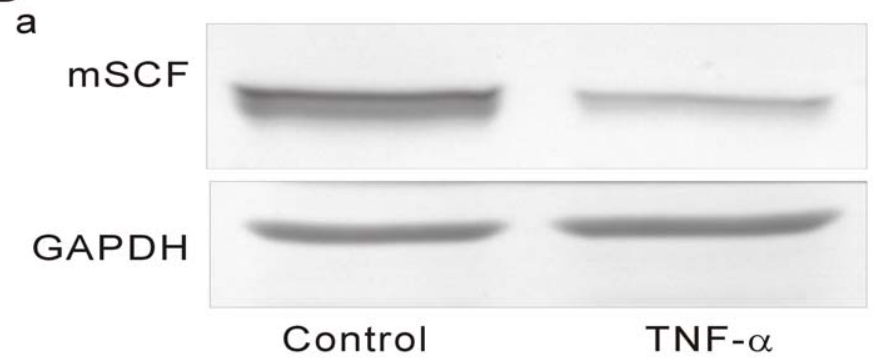

b

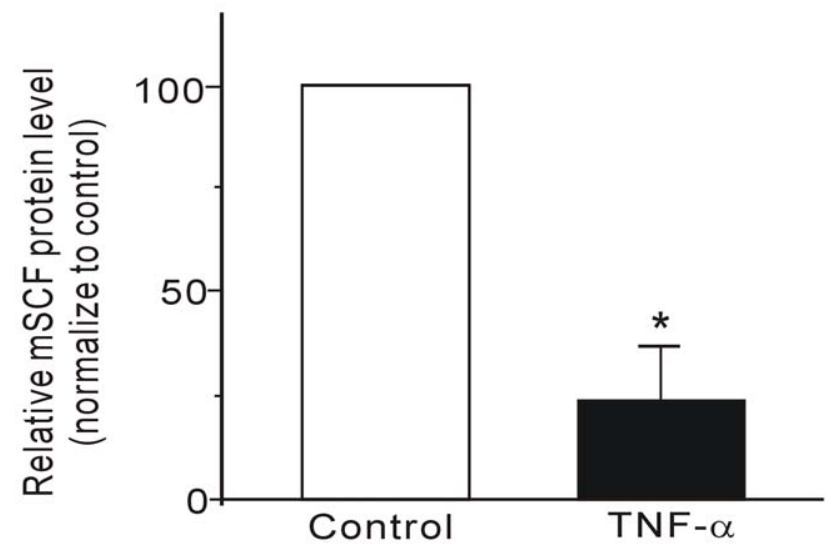

Figure 5. Effect of TNF- $\alpha$ on mSCF expression in cultured intestinal smooth muscle cells. Primary cultures of the intestinal smooth muscle cells are shown in (A). Intestinal smooth muscle cells displayed typical spindle-shaped morphology and a "hill-and-valley" pattern of growth (A-a). Immunofluorescence analysis of cultured intestinal smooth muscle cells revealed smooth muscle $\alpha$-actin (visualized with FITC-conjugated secondary antibody). DAPI was used to stain the nuclei (A-b). Western blotting revealed that expression of mSCF was significantly decreased in cultured intestinal smooth muscle cells treated with TNF- $\alpha(10 \mathrm{ng} / \mathrm{ml} ; B)$. A typical Western blot result is shown in (B-a). Bands were quantified using densitometry (compared with GAPDH and normalized to control; $\mathrm{B}-\mathrm{b}$ ). ${ }^{* *} \mathrm{P}<0.01, \mathrm{n}=8$. doi:10.1371/journal.pone.0048249.g005

\section{Discussion}

Thickening of the tunica muscularis in the gastrointestinal segment oral to an obstruction is a characteristic adaptation of the digestive tract in response to increased functional demands. The greatest increase in wall thickness occurs close to the obstruction, and results from both smooth muscle cell hyperplasia and hypertrophy. Gabella [4] and Won et al [8] reported that the intestinal walls of guinea pigs and rats with obstructed intestine showed hypertrophy proximal to the region of obstruction. In examinations of mouse models of intestinal obstruction, Chang et al [5] also reported that increase in the thickness of both circular and longitudinal muscle layers of the small intestine was due to increase in the number of cells. In the present study we also observed that obstructed mice intestine exhibited a marked increase in the thickness of the smooth muscle layers in the dilated region compared to those of control mice. These observations confirmed the morphological changes in intestinal smooth muscle layers presented previously in detail by Chang et al [5].

Since obstructed intestinal smooth muscle displayed distinctive structural remodeling, we continued to observe the mechanical and electrical activities of obstructed smooth muscle tissues in vitro. Our results demonstrated that both the frequency and the amplitude of slow waves were significantly decreased. Resting membrane potential of intestinal smooth muscle cells was depolarized 14 days after obstruction. These results were similar to previous studies $[5,8]$. These morphological and functional changes also indicated that this animal model is an appropriate study tool for investigations into consequences of intestinal obstruction.

To determine the relationship between ICGs and electrical dysfunction of obstructed smooth muscle, c-Kit expression was investigated. Maintenance of ICGs requires mSCF produced locally within the tunica muscularis [6,28,31]. Thus, in the present study, the expression of $\mathrm{mSCF}$ and c-Kit were observed in partially obstructed murine intestine. The results showed that both c-Kit and mSCF protein expression was clearly decreased in partially obstructed intestinal smooth muscle layers. ICG depletion may therefore be central to the pathogenesis of motility disorders. Previous studies in a model of obstructed rat ileum also demonstrated that disordered electrical slow waves were accompanied with the disruption of ICGs, along with the disruption of the corresponding network [5]. Consistent with these findings, our results suggest that obstruction-induced electrical dysfunction may be related to the loss of ICCs. Takeda et al [32] observed that reduction in the content of $\mathrm{mSCF}$ was also demonstrated in the stomach of non-obese diabetic (NOD) mice, which showed drastic depletion of ICGs and a one-third reduction in the expression of SCF. Reduction in both ICGs and expression level of SCF mRNA was more pronounced in NOD mice than in $\mathrm{db} / \mathrm{db}$ mice. In the present study, the obstruction-induced reduction in c-Kit expres- 
A

\section{CBS}

CSE

GAPDH
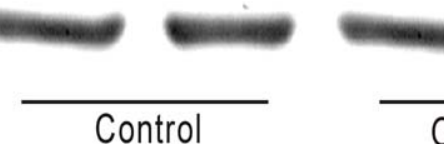

Control

\section{Obstruction}

B

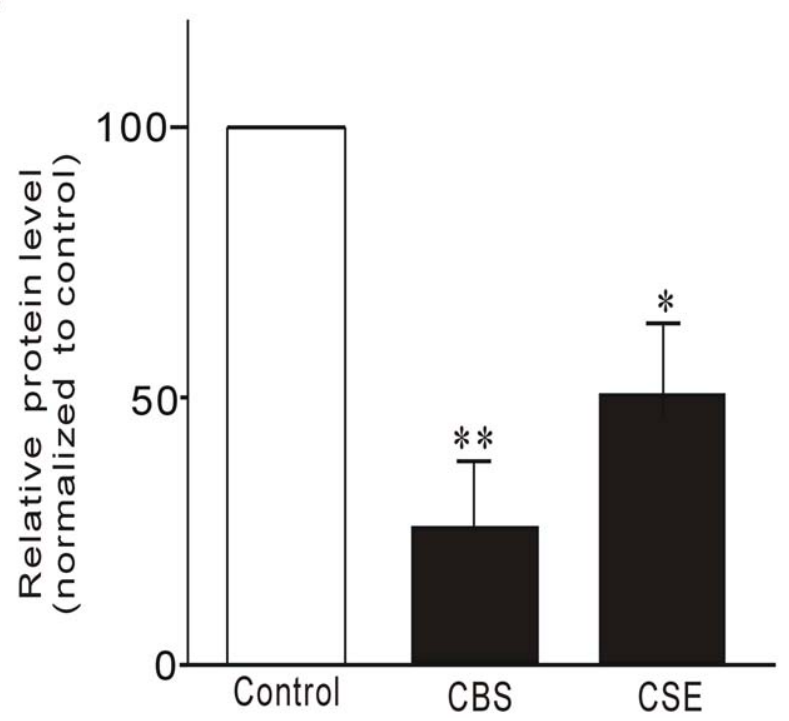

Figure 6. Western blot revealed decreased expression of CSE and CBS in obstructed ileal smooth muscle tissues. A representative blot is shown in (A), whilst the densitometric quantification (\%GAPDH and normalized to control) is depicted in (B). ${ }^{* *} \mathrm{P}<0.01, \mathrm{n}=8$. doi:10.1371/journal.pone.0048249.g006 sion was accompanied with decreased mSCF expression in obstructed smooth muscle tissue, suggesting that obstructioninduced reduction of $\mathrm{c}-\mathrm{Kit}$ expression was related to down regulation of $\mathrm{mSCF}$ expression in obstructed mice. It is unclear why mSCF expression in smooth muscle was suppressed since intestinal smooth muscle was significantly hypertrophic 14 days after partial obstruction.

mSCF serves as a link between smooth muscles and ICCs. Decrease in $\mathrm{mSCF}$ with smooth muscle atrophy underlies ICG loss in diabetic gastropathy and gastroparesis [6]. However, ICG loss in partial mechanical obstruction is known to accompany conditions in which smooth muscle mass is not reduced, but increased [6]. Further investigation into the mechanisms behind the reduction in $\mathrm{mSCF}$ protein expression is required. Toshihiko et al [16] reported that inflammation in smooth muscle is central to the loss of ICGs in a Hirschsprung disease model, in which animals have significant intestinal distension (megaileum). This distension was accompanied with the loss of ICCs proximal to a constricted region of the gastrointestinal tract lacking enteric ganglia. TNF- $\alpha$ was reported to have proinflammatory roles in this process and was significantly increased in the obstructed ileum [8]. We hypothesize that TNF- $\alpha$ might be involved in the reduction of $\mathrm{mSCF}$ expression in obstructed ileum. To test this hypothesis, we investigated the change of TNF- $\alpha$ in obstructed ileum and the effect of TNF- $\alpha$ on mSCF expression in cultured ISMGs. We found that TNF- $\alpha$ mRNA expression was significantly increased in the distended ileum in the obstructed group. TNF- $\alpha$ treatment suppressed the expression of mSCF protein in cultured ISMCs. These results suggest that obstruction-induced loss of ICGs or reduction of c-Kit expression is due to TNF- $\alpha$-mediated suppression of mSCF expression.

Although we demonstrated that TNF- $\alpha$ reduced the expression of $\mathrm{mSCF}$, the molecular mechanisms underlying this process need further investigation. $\mathrm{H}_{2} \mathrm{~S}$ has been demonstrated as an antiinflammatory factor $[21,22,25]$. We therefore investigated the expression of $\mathrm{H}_{2} \mathrm{~S}$ biosynthesis enzymes CBS and CSE to determine the role of endogenous $\mathrm{H}_{2} \mathrm{~S}$ during partial obstruction-induced inflammation. Our experiments demonstrated that CBS and CSE were both down-regulated while TNF- $\alpha$ expression was up-regulated in the same obstructed ileum. To further confirm the relationship between $\mathrm{H}_{2} \mathrm{~S}$ and $\mathrm{TNF}-\alpha$, we investigated the expression of TNF- $\alpha$ mRNA in small intestinal tissue after administerations of PAG, an inhibitor of CSE, and AOA, an inhibitor of CBA, via intraperitoneal injection. Inhibition of $\mathrm{H}_{2} \mathrm{~S}$
A

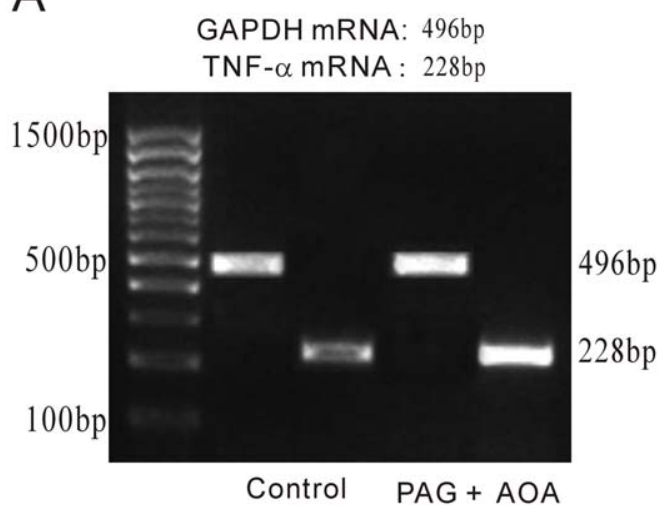

B

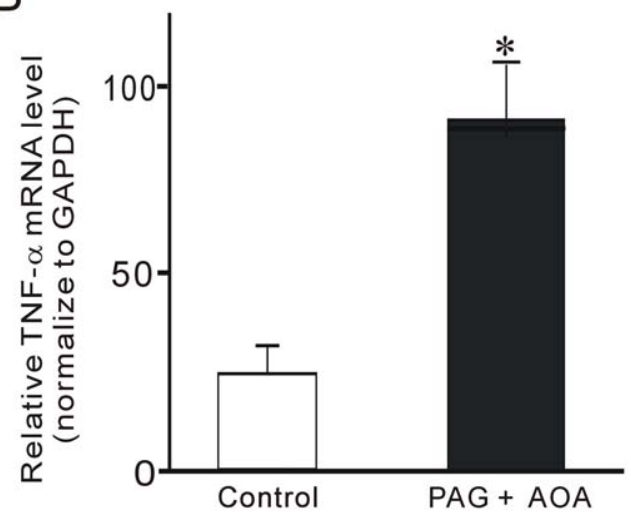

Figure 7. Effect of PAG and AOA on TNF- $\alpha$ mRNA expression in ileal smooth muscle tissues. (A) Expression of TNF- $\alpha$ and GAPDH mRNA. (B) Densitometric analysis of TNF- $\alpha$ and GAPDH mRNA. ${ }^{* * P}<0.01, n=8$. doi:10.1371/journal.pone.0048249.g007 


\section{GAPDH mRNA 496bp}

TNF- $\alpha$ mRNA 228bp

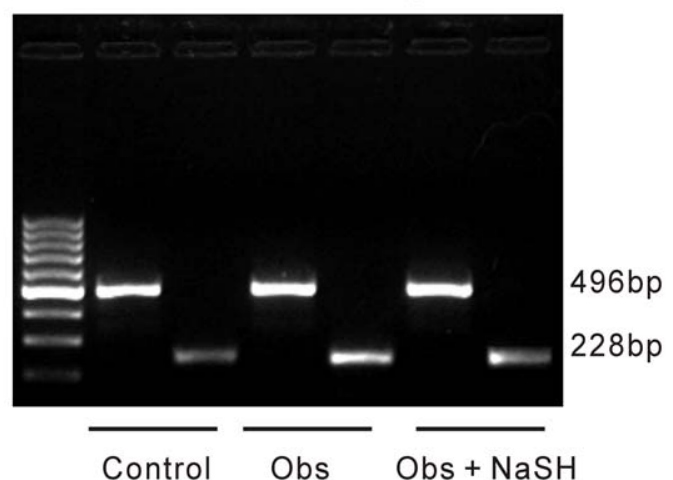

B

a

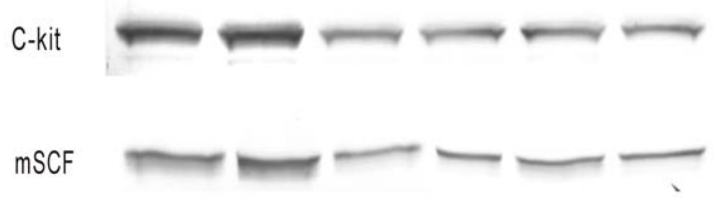

GAPDH

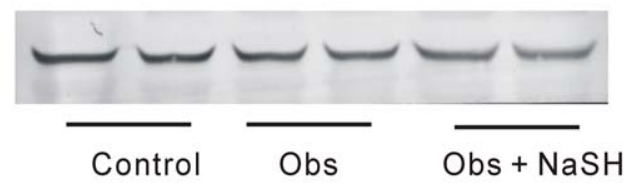

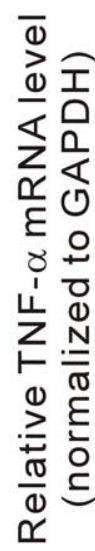

b

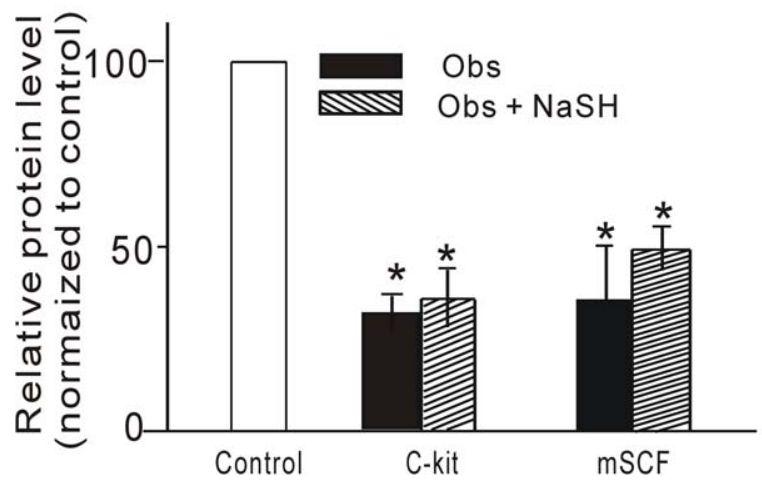

Figure 8. Effect of supplementation of $\mathrm{H}_{2} \mathrm{~S}$ on the expressions of TNF- $\alpha$ mRNA, mSCF and c-kit proteins in the obstructed ileal smooth muscle tissues. A shows the effect of supplementation of NaHS on TNF- $\alpha$ mRNA expression in obstructed intestinal smooth tissue. (Aa) Expression of TNF- $\alpha$ and GAPDH mRNA. (Ab) Densitometric analysis of TNF- $\alpha$ and GAPDH mRNA. B shows the effect of supplementation of NaHS on $\mathrm{mSCF}$ and c-kit protein expressions in obstructed intestinal smooth tissue. Representative western blot revealed different expression of mSCF and ckit (Ba), whilst the densitometric quantification (\%GAPDH and normalized to control) is depicted in (Bb). ${ }^{*} P<0.01$ vas control group; \# $P<0.01$ vas obstructed group. ( $\mathrm{n}=8$ )(obs: obstruction). doi:10.1371/journal.pone.0048249.g008

biosynthesis by PAG and AOA up regulated the expression of TNF- $\alpha$ mRNA in intestinal tissue [33]. Our results suggest that down-regulation of $\mathrm{H}_{2} \mathrm{~S}$ biosynthesis might be involved in obstruction-induced loss of ICG via up-regulation of TNF$\alpha$ expression, with the latter suppression of mSCF expression in intestinal smooth muscle. We further investigate the role of supplementation of exogenous $\mathrm{H}_{2} \mathrm{~S}$ by i.p NaHS $\left(\mathrm{a} \mathrm{H}_{2} \mathrm{~S}\right.$-releasing agent) in obstruction-induced over expression of TNF- $\alpha$ mRNA and down expressions of $\mathrm{mSCF}$ and c-kit proteins. The results demonstrated that supplementation of exogenous $\mathrm{H}_{2} \mathrm{~S}$ significantly improved obstruction-induced over expression of TNF- $\alpha$ mRNA, however, did not significantly enhanced the expressions of mSCF and c-kit proteins. Previous study confirmed that TNF- $\alpha$ involved in inflammation-induced loss of ICC [8] and our present study also observed TNF- $\alpha$ can suppress mSCF expression in cultured intestinal smooth muscle cells. Our results suggest that downregulation of $\mathrm{H}_{2} \mathrm{~S}$ biosynthesis might be involved in obstruction- induced loss of ICG via up-regulation of TNF- $\alpha$ expression, with the latter suppression of mSCF expression in intestinal smooth muscle. However, obstruction is very complicated pathophysiologic process so over expression is not one and only reason of loss ICC in obstructed intestinal smooth muscle tissue. Therefore, in despite of supplementation of exogenous $\mathrm{H}_{2} \mathrm{~S}$ significantly improved obstruction-induced over expression of TNF- $\alpha$ but not significantly restored the expressions of $\mathrm{mSCF}$ and c-kit proteins.

In summary, chronic partial mechanical obstruction of the small intestine induced a smooth muscle remodeling response to obstructive injury, for example, hyperplasia and hypertrophy, and was accompanied by electrical slow wave dysfunction. Obstruction-induced loss of ICCs may be related to $\mathrm{mSCF}$ down-regulation mediated by TNF- $\alpha$; TNF- $\alpha$ up-regluation is possibly induced by down regulation of endogenous $\mathrm{H}_{2} \mathrm{~S}$ biosynthesis in obstructed small intestine. However, over expression of TNF- $\alpha$ is not one and only reason of loss ICG in obstructed 
small intestine, many factors involved in obstruction-induced down expressions of $\mathrm{mSCF}$ and c-kit proteins.

\section{Supporting Information}

Figure S1 Morphological changes and H\&E stained in control and obstructed ileum. The open abdomen and dissection of the entire gastrointestinal tract of a control mouse (Aa). An arrow points to the portion of intestine bearing an opened ring of silicon tubing. 14 days after the creation of a partial obstruction (B-a). An arrow points to the portion of obstructed intestine bearing a ring of silicon tube and surgical thread. Crosssection of the ileum in control (A-b) and obstructed (B-b) mouse

\section{References}

1. Chitkara DK, Di Lorenzo C (2006) From the bench to the 'crib'-side: implications of scientific advances to paediatric neurogastroenterology and motility. Neurogastroenterol Motil. Apr; 18(4): 251-62. Review.

2. Jones MP, Wessinger S (2006) Small intestinal motility. Curr Opin Gastroenterol 22: $111-6$.

3. Storkholm JH, Zhao J, Villadsen GE, Hager H, Jensen SL, et al. (2007) Biomechanical remodeling of the chronically obstructed Guinea pig small intestine. Dig Dis Sci. Feb; 52(2): 336-46.

4. Gabella G (1990) Hypertrophy of visceral smooth muscle. Anat Embryol (Berl) 182: 409-24.

5. Chang IY, Glasgow NJ, Takayama I, Horiguchi K, Sanders KM, et al. (2001) Loss of interstitial cells of Cajal and development of electrical dysfunction in murine small bowel obstruction. J Physiol. Oct 15; 536: 555-68.

6. Horváth VJ, Vittal H, Lörincz A, Chen H, Almeida-Porada G, et al. (2006) Reduced stem cell factor links smooth myopathy and loss of interstitial cells of cajal in murine diabetic gastroparesis. Gastroenterology. Mar; 130(3): 759-70.

7. Yin J, Hou X, Chen JD (2006) Roles of interstitial cells of Cajal in intestinaltransit and exogenous electrical pacing. Dig Dis Sci. 51(10): 1818-23.

8. Won KJ, Suzuki T, Hori M, Ozaki H (2006) Motility disorder in experimentally obstructed intestine: relationship between muscularis inflammation and disruption of the ICC network. Neurogastroenterol Motil. Jan; 18(1): 53-61.

9. Huizinga JD, Zarate N, Farrugia G (2009) Physiology, injury, and recovery of interstitial cells of Cajal: basic and clinical science. Gastroenterology. 137(5): 1548-56. Review.

10. Huizinga JD, Thuneberg L, Klüppel M, Malysz J, Mikkelsen HB, et al. (1995) W/kit gene required for interstitial cells of Cajal and for intestinal pacemaker activity. Nature. Jan 26; 373(6512): 347-9.

11. Sandgren K, Larsson LT, Ekblad E (2002) Widespread changes in neurotransmitter expression and number of enteric neurons and interstitial cells of Cajal in lethal spotted mice: an explanation for persisting dysmotility after operation for Hirschsprung's disease? Dig Dis Sci. 47(5): 1049-64.

12. Sanders KM, Ward SM (2007) Kit mutants and gastrointestinal physiology. J Physiol. 578: 33-42. Review.

13. Ro S, Park C, Jin J, Zheng H, Blair PJ, et al. (2010) A model to study the phenotypic changes of interstitial cells of Cajal in gastrointestinal diseases. Gastroenterology. Mar; 138(3): 1068-78.

14. Lorincz A, Redelman D, Horváth VJ, Bardsley MR, Chen H, et al. (2008) Progenitors of interstitial cells of cajal in the postnatal murine stomach. Gastroenterology. Apr; 134(4): 1083-93.

15. Ekblad E, Sjuve R, Arner A, Sundler F (1998) Enteric neuronal plasticity and a reduced number of interstitial cells of Cajal in hypertrophic rat ileum. Gut. 42(6): 836- 44 .

16. Suzuki T, Won KJ, Horiguchi K, Kinoshita K, Hori M, et al. (2004) Muscularis inflammation and the loss of interstitial cells of Cajal in the endothelin ETB receptor null rat. Am J Physiol Gastrointest Liver Physiol. Sep; 287(3): G638-46.

17. Kilic A, Luketich JD, Landreneau RJ, Owens SR, Krasinskas AM, et al. (2008) Alterations in the density of interstitial cells of Cajal in achalasia. Dig DisSci. Jun; 53(6): 1488-92.

18. Yang G, Wu L, Jiang B, Yang W, Qi J, et al. (2008) H2S as a physiologic vasorelaxant: hypertension in mice with deletion of cystathionine gamma-lyase. Science. Oct 24; 322(5901): 587-90. tissue stained with hematoxylin-eosin $(\mathrm{H} \& \mathrm{E})$. In the obstructed intestine, there was a marked increase in the diameter of the ileum $(\mathrm{C}-\mathrm{a})$ and a marked increase in the thickness of both the longitudinal and circular muscle layers (C-b). Levels of significance compared to controls are indicated by asterisks $(* * \mathrm{P}<0.01, \mathrm{n}=8)$. (TIF)

\section{Author Contributions}

Conceived and designed the experiments: WX. Performed the experiments: XG XH YW DL HL YK. Analyzed the data: XG WX. Contributed reagents/materials/analysis tools: YW DL HL YK. Wrote the paper: WX XG.

19. Li L, Salto-Tellez M, Tan CH, Whiteman M, Moore PK (2009) GYY4137, a novel hydrogen sulfide-releasing molecule, protects against endotoxic shock in the rat. Free Radic Biol Med; 47: 103-113.

20. Whiteman M, Moore PK (2009) Hydrogen sulfide and the vasculature: a novel vasculo protective entity and regulator of nitric oxide bioavailability? J Cell Mol Med 13: 488-507.

21. Li L, Rossoni G, Sparatore A, Lee LC, Del Soldato P, et al. (2007) Antiinflammatory and gastrointestinal effects of a novel diclofenac derivative. Free Radic Biol Med. Mar 1; 42(5): 706-19.

22. Zanardo RC, Brancaleone V, Distrutti E, Fiorucci S, Cirino G, et al. (2006) Hydrogen sulfide is an endogenous modulator of leukocyte-mediated inflammation.FASEB J. Oct; 20(12): 2118-20.

23. Kalayarasan S, Sriram N, Sudhandiran G (2008) Diallyl sulfide attenuates bleomycin-induced pulmonary fibrosis: critical role of iNOS, NF-kappaB, TNFalpha and IL-1 beta. Life Sci. 82: 1142-1153.

24. Whiteman M, Li L, Rose P, Tan CH, Parkinson DB, et al. (2010) The effect of hydrogen sulfide donors on lipopolysaccharide-induced formation of inflammatory mediators in macrophages. Antioxid Redox Signal. May 15; 12(10): 1147 54.

25. Hirata I, Naito Y, Takagi T, Mizushima K, Suzuki T, et al. (2011) Endogenous hydrogen sulfide is an anti-inflammatory molecule in dextran sodium sulfateinduced colitis in mice. Dig Dis Sci. 56(5): 1379-86.

26. Chen J, Chen H, Sanders KM, Perrino BA (2008) Regulation of SRF/CArGdependent gene transcription during chronic partial obstruction of murine small intestine. Neurogastroenterol Motil. Jul; 20(7): 829-42.

27. Tan G, Pan S, Li J, Dong X, Kang K, et al. (2011) Hydrogen sulfide attenuates carbon tetrachloride-induced hepatotoxicity, liver cirrhosis and portal hypertension in rats. PLoS One 6(10): e25943.

28. He CL, Soffer EE, Ferris CD, Walsh RM, Szurszewski JH, et al. (2001) Loss of interstitial cells of cajal and inhibitory innervation in insulin-dependent diabetes. Gastroenterology. Aug; 121(2): 427-34.

29. Qi YX, Qu MJ, Long DK, Liu B, Yao OP, et al. (2008) Rho-GDP dissociation inhibitor alpha downregulated by low shear stress promotes vascular smooth muscle cell migration and apoptosis: a proteomic analysis. Cardiovasc Res. Oct1; 80(1): 114-22

30. Goto K, Chiba Y, Sakai H, Misawa M (2009) Tumor necrosis factor-alpha (TNF-alpha)induces upregulation of RhoA via NF-kappaB activation in cultured human bronchial smooth muscle cells. J Pharmacol Sci. Aug; 110(4): 437-44.

31. Wang XY, Albertí E, White EJ, Mikkelsen HB, Larsen JO, et al. (2009) Igflr+/ CD34+ immature ICG are putative adult progenitor cells, identified ultrastructurally as fibroblast-like ICC in Ws $/ W_{s}$ rat colon. J Cell Mol Med. Sep; 13(9B): 3528-40.

32. Iwasaki H, Kajimura M, Osawa S, Kanaoka S, Furuta T, et al. (2006) A deficiency of gastric interstitial cells of Cajal accompanied by decreased expression of neuronal nitric oxide synthase and substance $\mathrm{P}$ in patients with type 2 diabetes mellitus. J Gastroenterol. Nov; 41(11): 1076-87.

33. Gil V, Gallego D, Jiménez M (2011) Effects of inhibitors of hydrogen sulphide synthesis on rat colonic motility Br J Pharmacol. Sep; 164(2b): 485-98. 